\title{
APORIAS DO GLOBAL CONSTITUTIONALISM DE RICHARD FALK
}

\author{
ANDERSON V. TEIXEIRA*
}

\begin{abstract}
RESUMO: O artigo se propõe a fazer uma análise crítica da proposta de global constitutionalism de Richard A. Falk para a ordem internacional. O objetivo principal do presente artigo é expor os elementos e princípios básicos da referida proposta ao mesmo tempo em que se está tentando demonstrar como tais elementos e princípios possuem uma instrumentalização prática ou a sua própria argumentação filosófica maculada por alguma insuficiência teórica. PALAVRAS-CHAVE: Filosofia do Direito Internacional; Direitos Humanos; Constitucionalismo Global.
\end{abstract}

ABSTRACT: The article is proposed to make a critical analysis of the proposal of global constitutionalism presented by Richard A. Falk to the international order. The main scope of this article is to expose the basic elements and principles of that proposal while we are trying to demonstrate how those basic elements and principles have their practical instrumentalization or its philosophical argumentation maculated by some sort of theoretical insufficiency.

KEYWORDS: Philosophy of International Law; Human Rights; Global Constitutionalism.

SUMÁRIO: 1. Introdução; 2. A doutrina dos direitos humanos enquanto ideologia política; 3. Globalização vs Estado Nacional; 4. A universalidade da doutrina dos direitos humanos como princípio discursivo; 5 . O global constitutionalism; 6. Conclusão; 7. Bibliografia.

SUMMARY: 1. Introduction, 2. The doctrine of human rights as a political ideology, 3. Globalization vs. National State, 4. The universality of human rights' doctrine as a discursive principle, 5. The global constitutionalism; 6. Conclusion; 7. Bibliography.

\section{INTRODUÇÃO}

Durante as últimas três décadas do século XX e ainda no início do século XXI, Richard A. Falk ${ }^{1}$ se destacou construindo uma teoria político-filosófica que o coloca como um dos autores que mais contribuíram para a afirmação do universalismo jurídico como a (supostamente) melhor proposta a ser seguida pela comunidade internacional. A sua obra tem o mérito de ter mantido uma coerência interna mesmo tendo começado

\footnotetext{
* Doutorando em Filosofia do Direito pela Università degli Studi di Firenze (IT). Mestre em Direito do Estado pela PUC/RS. Professor dos cursos de graduação e pós-graduação da ULBRA/Torres. Advogado.

${ }^{1}$ R. Falk é professor emérito de 'International Law and Practice' na Universidade de Princeton há mais de quatro décadas. Em março de 2008, foi nomeado pelo Alto Comissariado de Direitos Humanos das Nações Unidas como investigador externo para a questão Palestina em Israel.
} 
a ser construída quando o mundo ainda era ideologicamente dividido em comunismo/ capitalismo, ou seja, entre EUA/URSS. Além disto, o pensamento do autor absorveu os efeitos dos diversos processos de globalização também de forma coerente com aquilo que ele vinha propondo - sobretudo nos seus escritos do início dos anos 80 do século passado -, como se pode ver no seu Predatory Globalization, de 1999.

"Institucionalismo pacifista”, “centralismo global”, "salvacionismo radical” e “globalismo jurídico” são algumas das rotulações que o trabalho de Falk costuma receber. Porém, adotaremos aqui o rótulo global constitutionalism, em virtude de ser este o mais adequado para explicar o fundamento teórico de sua proposta filosófica para o direito internacional.

Falk é na atualidade um dos expoentes mais influentes do universalismo jurídico de matriz kantiana. ${ }^{2}$ Desde a Liga das Nações, mas, sobretudo, após a criação da ONU, a inspiração kantiana se tornou flagrante na própria Carta das Nações Unidas e em diversos outros documentos legais que consagravam, expressa ou tacitamente, a "paz perpétua” como um ideal a ser buscado por todas as nações civilizadas. As mais significativas propostas de universalismo jurídico apresentadas durante o século XX sofreram algum tipo de influência pela Zum ewigen Frieden, a qual foi - e ainda é uma espécie de "profissão de fé cosmopolita” que inspirava tão profundamente juristas, filósofos, sociólogos e cientistas políticos, que Hedley Bull chegou a ironicamente denominá-los Western globalists. ${ }^{3}$

Ainda que o direito cosmopolita ${ }^{4}$ idealizado por Kant se resumisse a garantir a livre circulação de pessoas e bens de comércio por todo o mundo, permitindo que o estrangeiro fosse tratado como nacional, isto é, sem sofrer discriminação, em qualquer país que estivesse ${ }^{5}$, o autor alemão jamais demonstrou ter imaginado que algum dia $o$

\footnotetext{
${ }^{2}$ A "inaugurar" a adaptação do pensamento kantiano à ordem internacional podemos encontrar Hans Kelsen e o seu pacifismo jurídico como um marco inicial na filosofia do direito internacional. Nesta mesma tendência iniciada com Kelsen - e de certa forma seguida por Falk -, pode-se acrescentar ainda o trabalho dos seguintes filósofos, cientistas políticos e juristas: Norberto Bobbio, Jürgen Habermas, John Rawls e David Held.

${ }^{3}$ Cfr. Danilo Zolo, Globalizzazione. Una mappa dei problemi. Laterza, Roma-Bari, 2004, p. 71.

${ }^{4}$ No Terceiro Artigo definitivo do Zum ewigen Frienden, "Il diritto cosmopolitico deve essere limitato alle condizioni dell’ospitalità universale”, Kant afirmava que: “Ora, poichè la comunanza (più o meno stretta) tra i popoli della Terra, che alla fine ha dappertutto prevalso, si è arrivati a tal punto che la violazione di un diritto commessa in una parte del mondo viene sentita in tutte le altre parti, allora l'idea di un diritto cosmopolitico non appare più come un tipo di rappresentazione chimerica ed esaltata del diritto ma come un necessario completamento del codice non scritto sia del diritto politico sia del diritto internazionale verso il diritto pubblico dell'umanità, e quindi verso la pace perpetua, e solo a questa condizione possiamo lusingarci di essere in constante cammino verso di essa.” Immanuel Kant, Zum ewigen Frienden (1795), trad. it., Per la pace perpetua, Milano, Feltrinelli, 2005, p. 68.

5 "Esta idéia racional de uma comunidade pacífica perpétua de todos os povos da Terra (mesmo quando não sejam amigos), entre os quais podem ser estabelecidas relações, não é um princípio filantrópico (moral), mas um princípio de direito. A natureza encerrou todos os homens juntos, por meio da forma redonda que deu ao seu domicílio comum (globus terraqueus), num espaço determinado. E, como a posse do solo, sobre o qual o habitante da Terra foi chamado a viver, só pode ser concebida como a posse de uma parte de um todo determinado, por conseguinte, se uma parte sobre a qual cada um deles tem um direito primitivo, todos os povos estão originariamente em comunidade do solo; não em comunidade jurídica da posse (communio) e portanto de uso ou de propriedade desse solo; mas em reciprocidade de ação (commercium) física possível, isto é, numa relação universal de apenas um com todos os demais (relação
} 
grau de aproximação das relações interculturais e de superação dos limites geográficos pudesse chegar ao ponto que o atual mundo globalizado nos apresenta. Para Kant, o princípio do universalismo faria com que a violação do direito num lugar do mundo fosse sentida em toda parte, o que importaria dizer que alguém que fosse ofendido em um país que não é o seu de origem devesse ser tratado como se estivesse em sua própria nação.

De outra sorte, Falk conseguiu atingir a sua consagração acadêmica, ao longo da segunda metade do século XX, sustentando uma proposta baseada em princípios kantianos - como veremos, em especial, na idéia de transnational democracy -, mas adaptada ao contexto volátil e multidimensional apresentado pelos diversos processos de globalização.

\section{A DOUTRINA DOS DIREITOS HUMANOS ENQUANTO IDEOLOGIA POLÍTICA}

O primeiro ponto controverso na obra de Falk é como epistemologicamente ele aborda a doutrina dos direitos humanos. Tentando manter uma argumentação científica, supostamente restrita aos fundamentos teóricos da ordem político-jurídica internacional, o autor reiteradas vezes - e em diversos momentos - trata o tema dos direitos humanos como se este fosse uma ideologia política.

Ainda sob a égide da bipolarização política que dividiu o mundo durante a Guerra Fria, Falk sustentava que to promote human rights necessarily implies mounting an anticommunist ideological attack, with all that this portends for deteriorating SovietAmerican relations. ${ }^{6}$

De início, percebe-se que, assim como qualquer ideologia política, a contingência é a nota característica desta doutrina, tanto que Falk admite que:

"If Carter emphasis is abandoned or leads to his electoral repudiation, the status and cause of human rights is likely to be set back seriously. If it succeeds, even in part, the whole cycle of waning and waxing may be shifted slightly to the left, making space II (Governmental Settings) rather than space IV (Domestic Implementation of Human Rights in United States) the main focus for coalitionbuilding activities."

Deste modo, o autor, indiretamente, demonstra que a doutrina dos direitos humanos é substancialmente uma ideologia política, pois reconhece que a essência da proteção dos direitos humanos é produto de um confronto entre forças sociais opostas e não pode ser compreendida como uma atividade criadora de direitos ou como uma forma de persuasão racional. ${ }^{8}$ Se estivesse correta a naturalist notion de que alguns direitos são inerentes à natureza humana e que, simplesmente por isso, devem ser respeitados por qualquer

que consiste em se prestar a um comércio recíproco); e têm o direito de fazer a experiência, sem que por isto possa um estrangeiro tratá-los como inimigos. Este direito, como a união possível de todos os povos, com relação a certas leis universais de seu comércio possível, pode ser chamado de direito cosmopolítico (jus cosmopoliticum).” Immanuel Kant, Doutrina do Direito, São Paulo, Editora Ícone, 1993, pp. 201-202. ${ }^{6}$ Richard Falk, Human rights and State Sovereignty, N.Y.: Holmes\&Meier, 1981, p. 25.

${ }^{7}$ Ibidem, p. 30

8 "In essence, then, the protection of human rights is an outcome of struggle between opposed social forces and cannot be understood primarily as an exercise in law-creation or rational persuasion.” Ibidem, p. 34. 
sociedade civilizada, não ocorreria aquela que, segundo Falk, é a principal dificuldade da lógica naturalista: the vagueness of the norms and ambiguity of the mandate. ${ }^{9}$

A vagueza da prescrição normativa, a qual refere Falk, caracteriza a retórica dos direitos humanos, uma vez que é decorrência direta da pretensão universal que esta doutrina se propõe a alcançar. A indiferença pelo particular, pelas realidades próprias das comunidades regionais e nacionais, somada à necessidade que o conceito tem de restringir em sua própria existência lingüística toda a dimensão fenomenológica apresentada pelos mais variados povos, etnias e culturas, faz com que o conteúdo dos direitos humanos sempre venha a falhar em efetividade, seja pela vagueza ou pela demasiada precisão normativa.

Não obstante todos estes problemas decorrentes da estrutura epistemológica própria da lógica naturalista, o autor conclui que, em relação às demais lógicas por ele arroladas (statist, imperialist, globalist, transnationalist e populist), a naturalista é a que mais se adapta ao período de transição em que vivemos, pois ela helps to orient other ordering logics around emergent values, building a normative foundation and social consensus that will help create the sort of community sentiments needed if a beneficial form of world order is to be brought into being some time early in the twenty-first century. ${ }^{10}$

\section{GLOBALIZAÇÃO VS ESTADO NACIONAL}

Paralelamente e como conseqüência à ideologização que permeia - ou, melhor dizendo, fundamenta - a doutrina dos direitos humanos, vemos Falk repensar o conceito de Estado-nação na era da globalização.

O autor afirma que o modelo westphaliano ${ }^{11}$ está sendo gradualmente substituído por uma nova perspectiva normativa onde a dimensão territorial própria do Estado moderno não é mais um elemento impeditivo à comunicação e ao contato intercultural. ${ }^{12}$ O lado positivo desse displacement do Estado nacional da condição de único ator da política mundial seria a possibilidade de se pensar uma ordem internacional menos militarizada e mais propícia à solidificação de instituições globais. ${ }^{13}$ A erosão da

\footnotetext{
9 "The main difficulty with naturalist logic relates to the vagueness of norms and ambiguity of the mandate." Ibidem, p. 43

${ }^{10}$ Ibidem, p. 62.

${ }^{11}$ O "modelo westphaliano" surgiu com o encerramento da Guerra dos Trinta Anos (1618-1648), através da chamada Paz de Westphalia, simbolizada pela assinatura, em 24 de outubro de 1648, nas cidades de Münster e Osnabrück, de uma série de tratados que puseram fim à guerra que se iniciou tendo como uma das suas causas o conflito religioso entre a Respublica Christiana e as cidades-Estados luteranas e calvinistas situadas ao norte da Alemanha. As características mais significativas do modelo westphaliano, sob o ponto de vista político, foram a laicização do poder público e a afirmação do princípio de auto-determinação dos povos nas relações internacionais. Para um estudo maior sobre este tema, cfr. Leo Gross, The Peace of Westphalia, 1648-1948, in 'American Journal of International Law', 42 (1948) 1, pp. 20-41; Chris Brown, Sovereignty, Rights and Justice, Cambridge, Polity Press, 2002; Danilo Zolo, I Signori della pace, Roma, Carocci, 1998; Otto Brunner, Land und Herrschaft. Grundfragen der territorialen Verfassunsgeschichte Österreichs im Mittelalter, Wien, 1965, trad. it. Terra e potere, Milano, Giuffrè, 1983; e Antonio Cassese, International Law, Oxford, Oxford University Press, 2001.

${ }^{12}$ Cfr. Richard Falk, Predatory Globalization, Cambridge, Polity Press, 1999, p. 35.

${ }^{13}$ Cfr. Richard Falk, On Human Governance, cit., p. 79.
} 
soberania nacional ${ }^{14}$, caso fosse combinada com uma política global de human governance, ou seja, com uma agenda política internacional norteada pelos valores supostamente universais protegidos pela doutrina dos direitos humanos e guiado também por uma globalization-from-below ${ }^{15}$, permitiria transformar o papel da sociedade civil global em algo não meramente secundário, mas sim central na criação e condução das políticas globais. ${ }^{16}$

Falk chega a reconhecer que o enfraquecimento da soberania nacional não implica, necessariamente, no fortalecimento de uma geogovernance norteada pelo human interest, pois as forças dos mercados internacionais podem tomar o controle da política internacional e determinar a agenda desta a partir dos seus interesses econômicos. ${ }^{17}$ Ele também sustenta que uma mudança funcional na lógica da ordem internacional não implicaria em redução interna da autonomia política dos Estados ${ }^{18}$ - pressupondo que são absolutamente dissociáveis a soberania externa e a soberania interna de um Estado. Porém, o mais grave parece ser o fato de o autor subestimar o grau de consolidação e pressão que os mercados internacionais já gozam frente às economias locais e que, caso desaparecesse por completo a soberania nacional, somente tenderia a aumentar, enquanto que as estruturas de human governance propostas por ele são ainda muito incipientes ou inexistes.

Além disso, ao afirmar que os Estados que mais se beneficiam das prerrogativas advindas do poder soberano são os Estados que recentemente passaram por um período ditatorial ou neocolonial, Falk ignora totalmente o fato de que a soberania não é mera potência, ela também demanda ação - e possibilidades reais de ação -, sendo que os Estados por ele referidos quase sempre terminam por ceder diante do mínimo conflito com Estados mais industrializados, pois estes detêm o poder econômico, político e militar em medida suficiente para fazer suas vontades preponderarem quando em conflito com Estados de menor expressão no cenário internacional. ${ }^{19}$

${ }^{14}$ Sobre o tema da erosão da soberania nacional, cfr. Richard Falk, op. cit., pp. 96-103.

15 "These ideological and operational aspects of globalization are associated with the way in which transnational market forces dominate the policy scene, including the significant co-optation of state power. This pattern of development is identified here as 'globalization-from-above', a set of forces and legitimating ideas that is in many respects located beyond the effective reach of territorial authority and that has enlisted most governments as tacit partners. But globalization, so conceived, has generated criticism and resistance, both of a local, grass-root variety, based on the concreteness of the specifics of time and place - for example, the siting of a dam or a nuclear power plant or the destruction of a forest and on a transnational basis, involving the linking of knowledge and political action in hundreds of civil initiatives. It is this latter aggregate of phenomena that is described here under the rubric of 'globalizationfrom-below'. (...) What is the normative potential of globalization-from-below? The idea of normative potential is to conceptualize widely shared world order values: minimizing violence, maximizing economic well-being, realizing social and political justice, and upholding environmental quality.” Richard Falk, Predatory Globalization, cit., p. 130.

${ }^{16}$ Cfr. Richard Falk, On Human Governance, cit., p. 101.

${ }^{17}$ Cfr. Richard Falk, op. cit., p. 103.

${ }^{18} \mathrm{Cfr}$. Richard Falk, Human Rights and State Sovereignty, cit., p. 60.

19 "Nevertheless, the negative generalization holds even in the Third World to the extent that governing coalitions must rely on authoritarian prerogatives to sustain order. Since this condition pertains so widely, the most elaborate normative claim that can be advanced on behalf of the state as a framework for national life is that it has displayed an impressive capacity to assure an increasing measure of national autonomy for the peoples of the world, especially in those areas liberated from colonial rule in the last several decades. For these societies, the state as a political actor has achieved important goals, and is regarded by all parts 
Entretanto, Falk sustenta também que

“A world order critique of the state does not entail a call for its elimination as a form of political order. It argues in favor of eroding the dominance of the state, especially in the more industrialized societies, by enhancing governance structures of both international and intranational character. This process can and should proceed initially in the countries of the North, and then gradually be extended to the Third World. ${ }^{20}$,

Os fatos têm nos mostrado que aqueles que mais se valem das estruturas supranacionais de governance, seja na economia ou na política, são, via de regra, os países que formam a Tríade ${ }^{21}$, ou aqueles em desenvolvimento - como a Índia e a China, por exemplo - que são capazes de explorar a relação com algum dos membros da Tríade. ${ }^{22}$ Quando Falk sustenta a erosão do Estado nacional - ao invés de sua eliminação - em proveito do aprimoramento das governance structures of both international and intranational character, ele despreza um dos elementos mais importantes em qualquer processo de investigação que se proponha a apresentar proposições prescritivas: o elemento factual.

Falk considera que o Estado nacional possui o grande problema de ser constantemente envolvido em políticas que são destituídas de qualquer consideração pelos world order values. ${ }^{23}$ Os valores de tais políticas são orientados de modo que para cada passo dado avante um outro é dado para trás, uma vez que a burocracia estatal impede que sejam implementadas políticas de proteção dos direitos humanos. ${ }^{24}$

Porém, o modelo supranacional genuinamente universal defendido por ele, onde haveria espaço somente para aqueles países que deixassem de adotar formas de autoritarismo e reconhecessem os direitos humanos como universalmente válidos, seria também baseado em uma estrutura política que tende a repetir a mesma burocracia e vícios que caracterizam o Estado nacional. O fortalecimento das Nações Unidas - ou de qualquer outra estrutura supranacional com abrangência quase ilimitada e concentração de poder, como ocorre com a ONU - significaria a repetição do modelo estatal de gestão político-administrativa.

Poucos, certamente, discordariam do fato de que we need a growing number of influential individuals and groups who will think, feel, and act like planetary citizens,

of the political spectrum as a positive phenomenon. Such governing elites are not ready to relinquish their sovereignty to any external actor, whatever the global rationale, nor to diminish their internal control, even on behalf of ethnic groups pressing their own claims for autonomy and self-determination.” Ibidem, p. 99.

${ }^{20}$ Ibidem.

${ }^{21}$ Paul Hirst denomina Tríade o grupo formado por Estados Unidos, Europa e Japão, o qual, além de concentrar o investimento externo direto, também é responsável por ditar as regras da economia mundial. Cfr. Paul Hirst, The global economy: myths and realities, in 'International affairs', 73 (1997), p. 410; e P. Hirst e G. Thompson, Globalization in question, cit., pp. 02 e 70-73.

${ }^{22}$ Tratando especificamente desta temática, tomamos a liberdade de remeter ao nosso A relação indivíduo, Estado e empresa no contexto da globalização econômica, in 'Revista de Direito Empresarial' (Porto Alegre), Vol. 1, n 1 1, 2008, e Id., Globalização, soberania relativizada e desconstitucionalização do Direito, in Anderson V. Teixeira e Luis Antônio Longo, A Constitucionalização do Direito, Porto Alegre: Fabris Editor, 2008.

${ }^{23}$ Richard Falk, op. cit., p. 102.

${ }^{24}$ Ibidem. 
as well as fulfill traditional roles as loyal participants in local and national community processes $^{25}$; mas os efeitos concretos da influência desses planetary citizens na produção de políticas globais seriam mínimos - assim como o são hoje - quando confrontados com o poder de barganha que os grandes atores do cenário internacional gozam. H. Bull lembra que [F]orse è più probabile che un'autorità centralizzata rifletterà i valori delle grandi potenze oggi prevalenti, le sole ad avere la possibilita di metterla in atto. ${ }^{26}$

\section{A UNIVERSALIDADE DA DOUTRINA DOS DIREITOS HUMANOS COMO PRINCÍPIO DISCURSIVO}

Existe uma outra questão que merece ser brevemente referida: a questão do conteúdo material dos direitos humanos.

No Human Rights and State Sovereignty, de 1981, o autor critica o caráter autoritário de muitas formulações existentes no direito internacional sobre direitos humanos, reconhecendo, inclusive, que esta é uma doutrina peculiar ao liberalismo ocidental que procura ser aplicada como se fosse universal. ${ }^{27}$ Falk ainda acrescenta que reformulações no que diz respeito ao conteúdo e às prescrições dadas por tal doutrina precisam ser tratadas dentro de um contexto onde os países das mais diversas ideologias sejam ouvidos, mas, para tanto, ele considera que, não obstante as críticas existentes, a Declaração Universal dos Direitos do Homem e do Cidadão é um documento que se enquadra nos interesses de países não apenas capitalistas e ocidentais. ${ }^{28}$ Para ele, é como se todo o debate doutrinário existente entorno da própria validade universal de muitos dos direitos presentes em tal documento fosse mero debate entorno da efetividade ou instrumentalização de preceitos normativos existentes e incontestes. ${ }^{29}$

Como forma de aprimoramento do conteúdo do catálogo dos direitos humanos, o autor entende que é dentro de um contexto de global governance solidamente fundado em um projeto normativo, capaz de contar, sobretudo, com uma World Court, é que será possível que sejam rompidas as lógicas autoritaristas e pretorianas que

${ }^{25}$ Richard Falk, op. cit., p. 103.

${ }^{26}$ Hedley Bull, The Anarchical Society: a Study of Order in World Politics, London, Macmillan, 1977, trad. it. La società anarchica. L'ordine mondiale nella politica mondiale, Milano, Vita e Pensiero, 2005, p. 349.

${ }^{27}$ Cfr. Richard Falk, Human rights and State Sovereignty, op. cit., p. 137.

${ }^{28}$ Ibidem, p. 138.

${ }^{29}$ Para maiores informações sobre o debate quanto ao conteúdo dos direitos humanos, remetemos em especial a Luigi Ferrajoli, Diritti Fondamentali, Roma-Bari, Laterza, 2001. Veja-se também Antonio Cassese, I Diritti Umani Oggi, Roma-Bari, Laterza, 2005; Id, Umano-Disumano. Commissariati e prigioni nell'Europa di oggi, Roma-Bari, Laterza, 1994; Michael Ignatieff, Human Rights as Politics and Idolatry, Princeton, Princeton University Press, 2001; Robert Alexy, Theorie der Grundrechte. Frankfurt, Suhrkamp, 1985; Philip Alston Diritti umani e globalizzazione. Torino, EGA, 2005; Id. e Henry J. Steiner, International human rights in context, Oxford, Oxford University Press, 2000; Hedley Bull, Human rights and World politics, in R. Pettman, Moral claims in world affairs, London, Croom Helm, 1978; Jurgen Habermas e Charles Taylor, Multiculturalismo, Milano, Feltrinelli, 1998; Norberto Bobbio, L'Età dei Diritti, Torino, Einaudi, 1990; Luca Baccelli, Il particolarismo dei diritti. Roma, Carocci, 1999; Danilo Zolo, La giustizia dei vincitori. Roma-Bari, Laterza, 2006; Id., Fondamentalismo umanitario, in Michael Ignatieff, Una ragionevole apologia dei diritti umani, Milano, Feltrinelli, 2003; Norbert Rouland, Aux confins du droit. Anthropologie juridique de la modernité. Paris, Éditions Odile Jacob, 1991; Id., À propos des droits de l'homme: un regard anthropologique, in 'Droits fondamentaux', 3, 2003, pp. 129-151; Ingo Sarlet, A Eficácia dos Direitos Fundamentais, Porto Alegre, Livraria do Advogado, 2007; e Antônio Augusto Cançado Trindade, Tratado de Direito Internacional dos Direitos Humanos, Porto Alegre: Fabris Editor, 1997. 
preponderam nos países que não reconhecem ou não implementaram a doutrina dos direitos humanos. ${ }^{30}$ Em suma, ele propõe que se estabeleça um debate intercultural inclusive chamando ideologias distintas - sobre o conteúdo material dos direitos humanos, mas a priori ele já estabelece os princípios do discurso racional, as possibilidades de escolha que nós teremos e quais objetivos o debate deverá alcançar.

\section{O GLOBAL CONSTITUTIONALISM}

De acordo com Falk, a noção de global community é decisiva para que a concentração do poder político saía das mãos do Estado-nação e passe para a ordem supranacional, pois aquela noção é the animating ideal of an alternative world order system, leading to a dialectical emphasis on the unity of the whole and on the dignity of the individual and distinct substatal groups. ${ }^{31}$ Trata-se de um 'globalismo centralista', filosoficamente lockeano - em oposição à tradicional matriz hobbesiana das relações internacionais -, diretamente ligado às noções de "democracia transnacional” e de “constitucionalismo global”, tendo como norte a garantia da paz mundial e a proteção dos direitos humanos. ${ }^{32}$

O que ele propõe é um modelo de “constitucionalismo global” onde fosse criada uma estrutura supranacional destinada a tornar efetivos os direitos humanos independentemente das vontades dos líderes políticos dos Estados nacionais, uma vez que:

"Il costituzionalismo dovrebbe essere inteso, prima di tutto, come la complessa dinamica del 'costituire' attraverso iniziative democratiche, sotto gli auspici di donne e uomini di tutto il mondo che agiscono localmente, a livello di movimenti di base, all'interno di comunità politiche esistenti, e tuttavia con un occhio politico a un più vasto orizzonte di tempo e spazio. 'Costituire' è il principio democratico del costituzionalismo (agire localmente, pensare globalmente; impegno ora, in nome del dopo). ${ }^{33 \text { ", }}$

Segundo Falk, o “constitucionalismo global” pressupõe a existência de um quadro normativo jurídico que possa ser aplicado também frente às ações dos Estados, pois o fato de o direito internacional ser considerado um sistema de normas e regras torna-se de muito pouca ajuda quando não existem as estruturas formais de aplicação de tais normas e regras. ${ }^{34}$ Além disso, a pouca consideração que a opinião pública mundial nutre pelo direito internacional termina se constituindo em um resultado direto da incapacidade que os governos, em especial das grandes potências, demonstram quando o assunto é cumprir normas internacionais que sejam contrárias aos seus interesses. ${ }^{35}$ Para Falk, a criação de uma jurisdição obrigatória externa à realidade política interna dos Estados, juntamente com a criação de procedimentos judiciais de direito interno que garantam a efetividade das decisões da jurisdição internacional,

${ }^{30}$ Cfr. Richard Falk, On Human Governance, cit., pp. 249-250; e Id, Human rights and State Sovereignty, cit., pp. 181-182; e Id. Predatory Globalization, cit., pp. 182-184.

${ }^{31}$ Richard Falk, Human rights and State Sovereignty, op. cit., p. 182.

${ }^{32}$ Cfr. Danilo Zolo, Globalizzazione, cit., p. 72.

${ }^{33}$ Richard Falk in D. Held, D. Archibugi, R. Falk, M. Kaldor, Cosmopolis, Roma, Manifestolibro, 1993, p. 132.

${ }^{34}$ Ibidem, p. 148.

${ }^{35}$ Ibidem. 
seria uma forma de fazer avançar a tendência, surgida há séculos, de restringir cada vez mais o poder dos signori della guerra attraverso il diritto. ${ }^{36}$

O caráter "inicial” desta nova ordem projetada por Falk é fortemente questionado por H. Bull, pois, segundo este, ci dicono anche che dobbiamo dare vita a un nuovo inizio, e progettano un nuovo ordine mondiale, ma noi siamo nel mezzo di un processo, e non al suo inizio, e non si dà qualcosa come una 'nuova partenza'. ${ }^{37}$

Esse constitucionalismo global seria alcançado mediante a instituição de uma estrutura "quase-governativa" em escala internacional, mantendo relação à "lei fundamental” referida por Falk, qual seja, a Carta das Nações Unidas. ${ }^{38}$ Enquanto as condições históricas não se apresentam propícias a uma proposta de constitucionalismo global como esta - e não existe a mínima projeção de quando se darão tais “condições propícias” -, ele coloca a ação da sociedade civil global, das organizações nãogovernamentais de proteção de direitos humanos e de defesa do meio ambiente, além da atuação, dentro da própria ONU, de um grupo de trabalho destinado a preparare un insieme coerente di obiettivi e di proposte per sostanziare la richiesta di costituzionalismo globale. ${ }^{39} \mathrm{O}$ autor ainda afirma que os estudos deste grupo de trabalho deveriam defender l'idea di una seconda assemblea, eletta direttamente dalle popolazioni, all'interno delle Nazioni Unite, che avrebbe autorità concorrente alla selezione del segretario generale dell'ONU così come alle operazioni di messa in vigore del diritto e delle sanzioni sovranazionali. ${ }^{40}$ Conclui, sobre este tema, sustentando que o objetivo maior deste grupo de trabalho sarebbe quello di delineare i contorni di una politica globale dedicata alla pace, al benessere economico, ai diritti umani, alla democrazia e alla protezione ambientale. $^{41}$

D. Zolo opõe algumas objeções à proposta de Falk, por considerar que este parte de uma retórica universalista que vê o preâmbulo da Carta das Nações Unidas como fundamento para a ordem internacional, mas se esquece que a inteira estrutura constitucional da ONU é inspirada no modelo hierárquico da Santa Aliança, sendo que il compito di mantenere e ristabilire la pace è affidato, di fatto, ai soli membri permanenti del Consiglio di Sicurezza e la direzione strategica delle operazioni belliche è attribuita, di diritto, esclusivamente ai loro vertici militari. ${ }^{42}$

Analisando o global constitutionalism de Falk a partir da conjuntura políticojurídica internacional no pós-Guerra Fria, sobretudo após a consolidação, na última

\footnotetext{
${ }^{36}$ Richard Falk in D. Held, D. Archibugi, R. Falk, M. Kaldor, Cosmopolis, Roma, Manifestolibro, 1993, p. 148. ${ }^{37}$ Hedley Bull, op. cit., p. 350.

38 "Questo costituzionalismo globale rappresenterebbe una presenza istituzionale complessa su scala internazionale, con un carattere potenzialmente quasi-governativo e una presenza operativa all'interno di una cornice costituzionale priva di vincoli rigidi, a cui potrebbe essere conferito un contenuto più specifico facendo riferimento ad una legge fondamentale già esistente (ossia la Carta delle Nazioni Unite); potrebbe anche essere una azione mirata al conseguimento di alcuni princípi normativi che sono sanciti in modo inequivocabile nel diritto positivo internazionale.” Richard Falk in D. Held, D. Archibugi, R. Falk, M. Kaldor, Cosmopolis, cit., p. 135.

${ }^{39}$ Richard Falk in D. Held, D. Archibugi, R. Falk, M. Kaldor, Cosmopolis, cit., p. 155.

${ }^{40}$ Ibidem.

${ }^{41}$ Ibidem.

${ }^{42}$ Danilo Zolo, Cosmopolis, cit., p. 58.
} 
década do século XX, dos EUA como a única superpotência existente, D. Zolo aponta também que

“è poco realistica, infine, l’aspettativa che la massima potenza mondiale si impegni in una guerra che abbia le proporzioni, i rischi e i costi della Guerra del Golfo solo per ripristinare l'ordine internazionale e garantire la pace. Più realistico è considerare che dal punto di vista del governo degli Stati Uniti l'impegno a reagire alle violazioni dell'ordine internazionale coincide con l'impegno a ristabilire selettivamente lo status quo tutte le volte in cui — e soltanto quando — siano in gioco gli "interessi vitali” del paese. Non è un mistero che entro la strategia della global security rientrava la protezione degli interessi degli Stati Uniti nell'area del Golfo. ${ }^{43}$

Após ver sua obra receber críticas no sentido de ser 'utópica' ou 'idealista', a questão concernente à possibilidade de reforma das Nações Unidas é enfrentada por Falk em termos mais realistas em sua obra de 1999, Predatory Globalization. Aqui, ele enfrenta as críticas, sobretudo de $\mathrm{H}$. Bull, e reconhece que, mesmo sendo possível, é improvável uma reforma da ONU capaz de torná-la mais democrática e coerente com a doutrina dos direitos humanos. ${ }^{44}$ Entretanto, ele acena com a possibilidade de se combinar um Gandhismo e uma culture of human rights como instrumentos de pressão não institucionalizados, mas que necessariamente não deixariam de produzir efeitos, até mesmo reformadores, na estrutura da ordem internacional e, por conseqüência, na própria estrutura institucional da ONU. ${ }^{45}$

Ao se socorrer em tais argumentos, parece ter sido adotada uma cisão entre o racional e o metafísico na fundamentação de Falk. Até então, ele vinha sustentando sua argumentação em termos que remetiam a princípios lógico-racionais, mesmo que fossem meramente ideais, enquanto que ao apelar para o imponderável e o absolutamente contingente, citando como exemplos bem-sucedidos disto os casos do fim da Guerra Fria e o fim do apartheid na África do Sul, o autor dá claros sinais de que os seus fundamentos transcenderam os limites da lógica para retomar a antiga - e já utilizada em especial pelos sofistas da Grécia Antiga - transcendência metafísica como argumento final: o que importa não é o contexto atual, mas sim a possibilidade de mudança que as nossas ações podem causar no futuro, mesmo que tais possibilidades não apontem para um objeto racionalmente possível e o fim almejado seja viável somente a partir da ocorrência de algo transcendental à nossa realidade cognitiva atual. Entretanto, caso esse “ativismo mundial”, essa “academia de peacekeepers”, não venha

\footnotetext{
${ }^{43}$ Danilo Zolo, Cosmopolis, cit., p. 59.

${ }^{44}$ Cfr. Richard Falk, Predatory Globalization, Cambridge, Polity Press, 1999, p. 124.

45 "But it is not the only path that leads in such a direction. Another more radical possibility is by way of a displacement of political realism as the basis for governance at all levels of social organization. Such a displacement could take many forms, but perhaps the most appealing prospect from the vantage point of the present is some combination of Gandhism and what has come recently to be called 'the culture of human rights'. Such an aspirational future seems like a pipe dream at present; but, as observed earlier, only a decade ago so did a post-cold war world and a post-apartheid South Africa. How much such developments have occurred without the presence of concealed, yet latent and formidable, social forces committed to images of drastic reform that were condescendingly dismissed in realist circles as 'utopian' and 'irrelavant'? Presumably, such concealed opportunities for transformative politics exist in relation to the future of the United Nations and are worth commitment and struggle to actualize.” Ibidem.
} 
a atingir seus objetivos, H. Bull ironizava dizendo que caberá a uma versão moderna da Arca de Noé superar o Dilúvio e reconstruir o mundo com os "iluminados" que conseguiram sobreviver à destruição provocada pelo acirramento das guerras e por outros fatores como a poluição do meio ambiente. ${ }^{46}$

Outro ponto altamente problemático do pensamento de Falk e da sua proposta de global constitutionalism é a sua posição frente ao tema da jurisdição penal internacional.

Ele considera ter sido um sucesso o Tribunal de Nuremberg - passível de vir, até mesmo, a se tornar um modelo a ser seguido atualmente. ${ }^{47} \mathrm{~A}$ inovatividade deste Tribunal foi ter tentado atribuir responsabilidade penal aos líderes políticos por fatos ocorridos durante a Segunda Guerra Mundial, pois, de acordo com Falk, [T]he idea of individual responsability initiated so impressively, if imperfectly, at Nuremberg, needs to be extended to perpetrators of 'crimes against humanity' even when the abuses are associated in any way with a foreign war. ${ }^{48}$

$\mathrm{O}$ fato de ter tido os seus princípios legais fundamentais aprovados unanimemente pela recém-criada Assembléia Geral da ONU representaria um authoritative legal criteria to assess official behavior, and, consenquently, are embodied in modern internation law. ${ }^{49}$ É como se o caráter de exceção de tal Tribunal - o qual foi instituído apenas para julgar os japoneses e alemães vencidos na Segunda Guerra Mundial, tendo sido os "juízes” indicados apenas pelos países vencedores - tivesse sido sublimado pela "unanimidade” que foi a sua aprovação.

Mesmo defendendo o modelo de Nuremberg, o autor acrescenta que, devido às pressões advindas da ordem internacional, a qual se apresenta como sendo notadamente imperialista, é pouco razoável pensar que um Tribunal semelhante pudesse se tornar um permanent institutional framework. ${ }^{50}$ As novas elites surgidas em países de Terceiro Mundo, as quais muitas vezes não se submetem aos padrões morais e legais da comunidade internacional, constituir-se-iam em outro empecilho à efetividade de

46 "Per elaborare questa struttura politica Falk prospetta un programma caratterizzato da «attivismo mondiale», «crescita della consapevolezza», attraverso «dichiarazioni di emergenza ecologica», «università della sopravvivenza», «accademie dei peacekeeper», un partito politico mondiale, e (per premunirsi di fronte alla possibilità che questi sforzi falliscano e che un equivalente moderno del Diluvio si realizzi) una «arca del rinnovamento», che consentirà ad un nucleo sopravvissuto di illuminati di ricostruire il mondo." Hedley Bull, op. cit., pp. 347-348.

${ }^{47}$ Ressalte-se que nem mesmo H. Kelsen, cuja obra influenciou indiretamente aquele Tribunal, veio a considerar um sucesso o ocorrido em Nuremberg. Em H. Kelsen, Will the judgment in the Nuremberg Trial constitute a precedent in International Law? in 'International Law Quarterly', 1 (1947) 2, p. 156, o autor dizia que: "To deduce individual criminal responsibility for a certain act from the mere fact that this act constitutes a violation of international law, to identify the international illegality of an act by which vital human interests are violated with its criminality, meaning individual criminal responsibility for it, is in contradiction with positive law and generally accepted principles of international law.” Para um maior estudo sobre a questão Nuremberg, veja-se, em especial: Danilo Zolo, La giustizia dei vincitori, cit.; George A. Finch, The Nuremberg Trial and International Law, in 'American Journal of International Law', 41 (1947) 1, pp. 20-37; e Quincy Wright, The Law of the Nuremberg Trial, in 'American Journal of International Law', 41 (1947) 1, pp. 38-72.

${ }^{48}$ Richard Falk, Human rights and State Sovereignty, cit., p. 05.

${ }^{49}$ Ibidem, p. 195.

${ }^{50}$ Ibidem, p. 196. 
qualquer decisão tomada por um Tribunal internacional com semelhante finalidade e abrangência. ${ }^{51}$ No entanto, novamente, Falk pauta seu pensamento pela construção de uma ideal sociedade global capaz de superar tais problemas, os quais são, ao nosso sentir, inerentes ao atual modelo de sistema internacional e serão também a qualquer outro modelo de matriz universalista, sobretudo kantiana.

Refira-se também que, assim como ocorre em inúmeros momentos ao longo de toda a obra de Falk, o problema da inefetividade dos direitos humanos tende a sempre ter como causa maior os países de Terceiro Mundo e suas pouco confiáveis instituições públicas, cabendo apenas restritas críticas às violações de direitos humanos e de normas de direito internacional perpetradas por países da Tríade, em especial pelos EUA. ${ }^{52}$

\section{CONCLUSÃO}

Por fim, esperamos ter apresentado um panorama geral de como o global constitutionalism de Falk se coloca como um projeto político-jurídico para a ordem internacional, onde aquele conceito surge como instrumento formal para a afirmação de uma "democracia transnacional” baseada na: (1) eficácia do direito internacional, (2) na tutela dos direitos humanos e (3) na busca da paz mundial em um planeta ecologicamente equilibrado.

Todavia, pode-se sintetizar, no que concerne aos fundamentos da ordem internacional, as insuficiências teóricas da obra de Falk da seguinte forma:

a) ignorar a pressão voluntarista exercida pelos líderes das grandes potências na formação das agendas políticas e dos órgãos internacionais, o que gera uma desigualdade material entre os Estados;

b) superestimar a capacidade de pressão e atuação da global civil society no processo de formação destas agendas políticas internacionais e na sua instrumentalização através das instituições político-jurídicas de abrangência global;

c) tomar a doutrina dos direitos humanos como sendo um dos fundamentos da atual ordem internacional reconhecido como legítimo universalmente, ainda que Falk admita que se trata de um discurso claramente ideológico;

d) centralizar as estruturas de administração global em instituições que pouco possuem de diverso em relação aos atuais - e falhos - modelos presentes na ordem internacional, como ocorre com o caso da jurisdição penal internacional;

e) definir proposições normativas universalmente válidas a partir da conjuntura descritiva apresentada somente pelo Oeste, mais especificamente, pelos países detentores do poder econômico e político, presumindo que o resto do mundo aceite passivamente entrar em um debate conceitual onde tanto as bases epistemológicas quanto os objetivos do debate já estão pré-definidos.

\footnotetext{
${ }^{51}$ Richard Falk, Human rights and State Sovereignty, cit., p. 196.

${ }^{52}$ Somente nos últimos anos Falk - em co-autoria com Howard Friel, Israel-Palestine on Record: How the New York Times Misreports Conflict in the Middle East, London, Verso Books, 2007 - enfrentou diretamente a questão palestina e as acusações constantes de violações aos direitos humanos cometidas por Israel.
} 


\section{BIBLIOGRAFIA}

ALEXY, Robert. Theorie der Grundrechte. Frankfurt: Suhrkamp, 1985.

ALSTON, Philip. Diritti umani e globalizzazione. Torino: EGA, 2005.

; STEINER, J. Henry. International Human Rights in Context. Law, Politics and Morals. Oxford: Oxford University Press, 2000.

BACCELLI, Luca. Il particolarismo dei diritti. Roma: Carocci, 1999.

BOBBIO, Norberto. L'età dei diritti. Torino: Einaudi, 1997.

BROWN, Chris. Sovereignty, Rights and Justice. Cambridge: Polity Press, 2002.

BRUNNER, Otto. Land und Herrschaft. Grundfragen der territorialen Verfassunsgeschichte Österreichs im Mittelalter. Wien, 1965, trad. it. Terra e potere. Milano: Giuffrè, 1983.

BULL, Hedley. The Anarchical Society: a Study of Order in World Politics. London, Macmillan, 1977, trad. it. La società anarchica. L'ordine mondiale nella politica mondiale. Milano: Vita $\mathrm{e}$ Pensiero, 2005.

Human rights and World politics, in Pettman, Ralph. Moral claims in world affairs. London: Croom Helm, 1978.

CASSESE, Antonio. I Diritti Umani Oggi. Roma-Bari: Laterza, 2005. International Law. Oxford: Oxford University Press, 2001.

1994. . Umano-Disumano. Commissariati e prigioni nell'Europa di oggi. Roma-Bari: Laterza,

FALK, Richard. Predatory Globalization. Cambridge: Polity Press, 1999. . e Friel, Howard. Israel-Palestine on Record: How the New York Times Misreports Conflict in the Middle East. London: Verso Books, 2007. . The Promise of World Order. Philadelphia: Temple University Press, 1987. . On Human Governance. Towards a New Global Politics. Cambridge: Polity Press, 1995. . The Status of Law in International Society. Princeton: Princeton University Press, 1970. Human Rights and State Sovereignty, New York: Holmes and Meier, 1981.

FERRAJOLI, Luigi. Diritti Fondamentali. Roma-Bari: Laterza, 2001.

FINCH, George A. The Nuremberg Trial and International Law, in 'American Journal of International Law', 41 (1947) 1, pp. 20-37.

GROSS, Leo. The Peace of Westphalia, 1648-1948, in 'American Journal of International Law', 42 (1948) 1, pp. 20-41.

HABERMAS, Jürgen; e TAYLOR, Charles. Multiculturalismo. Lotte per il riconoscimento. Milano: Feltrinelli, 1998.

HELD, David; FALK, Richard; ARCHIBUGI, Daniele. Cosmopolis. Roma: Manifestolibro, 1993. HIRST, Paul. The global economy: myths and realities, in 'International affairs', 73 (1997), pp. 409-427.

; Thompson, Grahame. Globalization in question. Cambridge: Polity Press, 1999.

IGNATIEFF, Michael. Human Rights as Politics and Idolatry. Princeton: Princeton University Press, 2001.

KANT, Immanuel. Zum Ewigen Frieden (1795), trad. it. Per la pace perpetua. Milano: Feltrinelli, 2005.

Doutrina do Direito. São Paulo: Editora Ícone, 1993. 
KELSEN, Hans. Will the judgment in the Nuremberg Trial constitute a precedent in International Law? in 'International Law Quarterly', 1 (1947) 2, pp. 153-171

ROULAND, Norbert. Aux confins du droit. Anthropologie juridique de la modernité. Paris: Éditions Odile Jacob, 1991.

. À propos des droits de l'homme: un regard anthropologique, in 'Droits fondamentaux', 3 (2003), pp. 129-151.

SARLET, Ingo. A Eficácia dos Direitos Fundamentais. Porto Alegre: Livraria do Advogado, 2007.

TEIXEIRA, Anderson V. Estado de Nações. Porto Alegre: Fabris Editor, 2007.

. A relação indivíduo, Estado e empresa no contexto da globalização econômica, in 'Revista de Direito Empresarial' (Porto Alegre), Vol. 1, n. 1, 2008.

. Globalização, soberania relativizada e desconstitucionalização do Direito, in Id.; e LONGO, Luis Antônio. A Constitucionalização do Direito. Porto Alegre: Fabris Editor, 2008.

TRINDADE, Antônio Augusto Cançado. Tratado de Direito Internacional dos Direitos Humanos. Porto Alegre: Fabris Editor, 1997.

WRIGHT, Quincy. The Law of the Nuremberg Trial, in 'American Journal of International Law', 41 (1947) 1, pp. 38-72.

ZOLO. Danilo. La giustizia dei vincitori. Roma-Bari: Laterza, 2006. . Globalizzazione. Una mappa dei problemi. Roma-Bari: Laterza, 2004.

. Fondamentalismo umanitario, in Michael Ignatieff. Una ragionevole apologia dei diritti umani. Milano: Feltrinelli, 2003.

. Cosmopolis. Milano: Feltrinelli, 2001.

. I Signori della pace. Roma: Carocci, 1998. 